Научная статья

УДК 811.161.1:82-14

DOI: $10.18101 / 2307-3330-2021-4-92-96$

\title{
ОБ ИЗУЧЕНИИ ПОЭТИЧЕСКИХ ТЕКСТОВ НА УРОКАХ ПО РУССКОМУ ЯЗЫКУ КАК ИНОСТРАННОМУ
}

\section{(с) Улазаева Галина Васильевна}

кандидат филологических наук, доцент, Бурятский государственный университет имени Доржи Банзарова Россия, 670000, Улан-Удэ, Смолина, 24а diskurs@mail.ru

\section{(C) Хабдаева Аюна Константиновна доктор философских наук, доцент, Байкальский государственный университет Россия, 664003, г. Иркутск, ул. Ленина, 11 ayupost@yandex.ru}

\begin{abstract}
Аннотация. Введение иностранного учащегося в культурную среду изучаемого языка является одной из важных задач в преподавании русского языка как иностранного (РКИ). И одно из средств реализации этой задачи - изучение русской поэзии. Работе с поэтическими текстами на уроках РКИ отводится особое место. Художественный текст представляет собой эффективное средство, приближающее иностранных учащихся к естественной языковой и культурной среде, это отдельная модель национальной культуры. Исходя из принципа тесной взаимосвязи языка и культуры важно знакомить иностранных учащихся с культурой разных народов, живущих на территории России. В статье дается пример самостоятельного познания и восприятия иностранными учащимися стихотворения известного бурятского поэта Баира Дугарова «Звезда кочевника», пишущего на русском языке.
\end{abstract}

Ключевые слова: русский язык как иностранный, социокультурная компетенция, модель национальной культуры, два языковых мира, поэтический текст, перевод.

\section{Для цитирования}

Улазаева Г. В. Хабдаева А. К. Об изучении поэтических текстов на уроках по русскому языку как иностранному // Вестник Бурятского государственного университета. Образование. Личность. Общество. 2021. № 4. С. 92-96.

Известно, что в практике преподавания русского языка как иностранного (РКИ) особое место отводится работе с поэтическими текстами. Практика показывает, что удачно подобранный художественный текст (в т. ч. поэтический) дает возможность, вопервых, сделать урок интересным, во-вторых, помогает увлечь учащихся процессом самостоятельного познания и восприятия текста, а это, несомненно, мотивирует их изучать русский язык. Методисты рекомендуют не только подбирать интересные тексты, но и должным образом планировать и организовывать работу над любым текстом как естественный процесс общения читателя с книгой.

Художественный текст представляет собой эффективное средство, приближающее иностранных учащихся к естественной языковой и культурной среде. Н. В. Кулибина считает, что художественный текст является «трижды культурным объектом», так как: 1) в 
Г. В. Улазаева, А. К. Хабдаева. Об изучении поэтических текстов на уроках по русскому языку как иностранному

художественной литературе отражена вся жизнь народа, в том числе и культура как важнейшая ее составляющая, 2) язык — «материал», из которого «изготовлен» художественный текст, - важнейший культурный феномен, 3) художественный текст - артефакт культуры [Кулибина, с. 60].

В статье «Художественный текст на уроках русского языка как иностранного» Р. В. Миксюк указывает: «Каждый художественный текст представляет собой отдельную модель национальной культуры, содержащую информацию о национальных личностных характеристиках и образе жизни, о явлениях и поступках, одобряемых или порицаемых в контексте изучаемой культуры» [Миксюк, с. 62]. С данным утверждением также нельзя не согласиться. Чтобы понять культуру другой страны, необходимо, бесспорно, чтение литературных произведений. А русская литература, мы знаем, покорила весь мир.

Что касается литературного рода, то стало уже традицией при обучении иностранному языку обращение прежде всего к эпическим произведениям. Но и поэтические произведения находят свое место в практике преподавания языка уже на достаточно раннем этапе обучения.

Литературовед, профессор Литературного института Владимир Смирнов говорил: «Мы отчасти обречены на особую связь с поэзией из-за нашего пейзажа, ландшафта. Сердце и душа чувствуют: то, что мы называем жизнью природы, — на самом деле нечто большее, нечто совершенно другое. Поэзия приближает нас к этому «нечто». ... Великая русская литература - а она несводима только к Толстому и Достоевскому — грандиозна. И мир изумлен ею» [Смирнов, URL: https://ufa.bezformata.com/listnews/poeziya-v-rossiiravnovelika-religii/97817520/].

Итак, введение учащегося-иностранца в культурную среду изучаемого языка является одной из важных задач в преподавании РКИ. И одно из средств реализации этой задачи - изучение поэзии на уроках РКИ. Вся классическая русская поэзия обладает глубоким смыслом, лаконичным языком, красивой формой. Учитывая то, что в России поэзия имеет великую значимость, мы не можем не знакомить наших студентов с русской литературой, с русской поэзией, погружение в которую происходит, безусловно, постепенно. На уроках по чтению, по русской литературе мы с нашими студентами изучаем стихи разных поэтов, анализируем, обсуждаем, переводим, читаем наизусть. Принимаем участие в самых разных поэтических конкурсах, проводимых в нашем университете, а также в библиотеках нашего города.

Отметим, что в копилке магистерских диссертаций наших иностранных учащихся есть работы, посвященные изучению методов, приемов и форм работы при обучении чтению лирики.

По мнению Н. В. Кулибиной, стихотворные тексты имеют неоспоримые преимущества. «Что касается распространенного мнения о том, что многие не любят стихи, то ответ прост: не умеют, не пробовали, боятся ...» [Кулибина, 2008, с. 13].

Исходя из принципа тесной взаимосвязи языка и культуры, безусловно, важно знакомить иностранных учащихся с культурой разных народов, живущих на территории России. Рассмотрим стихотворение известного бурятского поэта Баира Дугарова «Звезда кочевника».

В этом философском стихотворении даны символы кочевого пространства, образы кочевника, всадника, пути. Иностранные учащиеся видят образы мужчины-бурята и женщины-бурятки. Рассуждают о смысле жизни, менталитете, предначертанности человека, живущего на земле, о любви. Отметим, что изучение стихотворений Б. Дугарова вызвало живой интерес у иностранных студентов (изучали со студентами продвинутого этапа обучения). 
Очевидно, чтение художественных произведений бурятских авторов может помочь глубже понять особенности культуры бурятского народа, составляющего значимую часть населения Российской Федерации. Огромный вклад в бурятскую литературу вносит Баир Сономович Дугаров, это один из ведущих поэтов Бурятии. Его творчество вызывает уважение, восхищение. С чувством гордости мы знакомим иностранных учащихся с его творчеством, благодаря его произведениям у нас есть уникальная возможность познакомить представителей других культур с культурой бурятского народа.

Б. Дугаров пишет на русском языке. О том, почему он выбрал для поэтического самовыражения не родной бурятский, а русский язык, рассуждает профессор С. С. Имихелова. То, что Б. Дугаров сумел наиболее полно выразить свое творческое «я» не на родном языке, заложено уже в его детстве, которое вначале прошло в горной Оке, а затем в хоринской степи, в русской деревне, где мальчик познакомился с живой русской речью, и русско-бурятский билингвизм с детства стал постоянным средством общения. При этом поэт уникальным образом сохраняет и создает в своем творчестве свою бурятскую, монгольскую картину миру [Имихелова, с. 46].

Сам поэт в одном из интервью вспоминает следующее: «Сидевший рядом знаменитый поэт Дондок Улзытуев, посмотрев мои стихи, сказал: «Парень пишет на русском, а чувствуется бурятское» [URL: https:/minkultrb.ru/news/news/12375-bair-dugarovcheloveku-nuzhno-popast-v-sredu-sebe-podobnykh/].

«Народ интересен своими мыслителями, поэтами, которые сумели обозначить те символы, которые воплощают идеи нации. Параллельно осмысливая два языковых мира, Баир Дугаров наиболее полно сумел выразить на русском языке свою ментальную сущность. Богатство «концептосферы» его лирики тесно связано с богатством культуры бурятской нации и с русским языком, основным выразителем евразийского пространства», - пишет Л. С. Дампилова в предисловии к книге стихотворений Б. С. Дугарова «Струна земли и неба» [Дугаров, с. 3].

В качестве дополнительного задания можно предложить учащимся сделать перевод указанного стихотворения на родной язык. Перевод, как известно, представляет собой самостоятельный вид речевой деятельности, этот методический прием позволяет оптимизировать учебный процесс. Переводя с одного языка на другой, учащиеся используют как свои языковые знания, так и экстралингвистические знания, так как сталкиваются не только с лингвистическими проблемами, но и с комплексом культурных различий между языковыми сообществами. Среди наших студентов всегда находятся желающие сделать перевод предлагаемых стихотворений на родной язык. Каким образом суметь передать идею произведения, его настроение, дух стихотворения, авторский замысел? Задача, безусловно, непростая.

Приведем в качестве примера перевод «Звезды кочевника» на тайский язык (переводил тайский магистрант). Задания были даны такие: 1) напишите небольшой отзыв о прочитанном стихотворении, 2) попробуйте сделать перевод на родной язык.

\section{Звезда кочевника}

Мужчине - путь, а женщине - очаг. И чтобы род мой древний не зачах, роди - молю и заклинаю - сына. Стрела летит, покуда жив мужчина.

Мужчине - дым, а женщине - огонь. И чтоб в бою мой не споткнулся конь, я должен знать, что юрту греет пламя, как предками завещанное знамя.

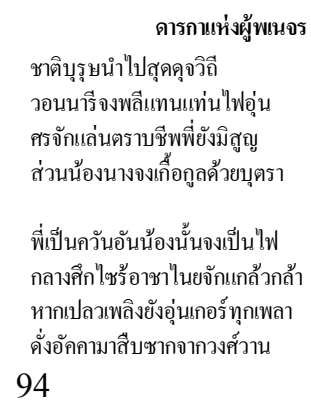


Г. В. Улазаева, А. К. Хабдаева. Об изучении поэтических текстов на уроках по русскому языку как иностранному

\begin{tabular}{|c|c|}
\hline $\begin{array}{l}\text { В мужчине — дух, а в женщине — душа. } \\
\text { Травинка держит небо трепеща. } \\
\text { Без очага, без сына, без любимой, } \\
\text { как одинокий смерч, развеюсь над равниной. }\end{array}$ & $\begin{array}{l}\text { ชาตรีคู่นารีไซร้ใจคู่จิต } \\
\text { หญ้ายังลิดสะกิดฟ้าให้สั่นสาน } \\
\text { ปราศเปลวไฟไร้รักบุตรสุดต้านทาน } \\
\text { ดั่งลมบ้ากระซ่าซ่านอันตรธานไป }\end{array}$ \\
\hline
\end{tabular}

Приведем фрагмент отзыва тайского магистранта: «Образ жизни тайцев очень отличается от образа жизни бурят. Если бы я не приехал учиться в Бурятию, я бы никогда не понял, как буряты жили и живут, и не понял бы смысла этого стихотворения. Это стихотворение мне очень понравилось тем, что оно имеет глубокое значение. В произведениях тайских поэтов нет образов кочевников. Но дух этого стихотворения мне понятен. Поэт здесь затрагивает семейные отношения ... . Без помощи доброй хозяйки мужчина со всеми делами не может справиться. ... Семья всегда ждет, когда невестка родит здорового сына. И то, что жена должна ждать хозяина дома - мужчину, что должна заботиться о доме, представляется тайцу естественным... .».

Интересным заданием может быть такое: послушайте песню на эти стихи в исполнении известных бурятских музыкантов Саяны и Эржены Жамбаловых. Практика показывает, что аутентичные песенные тексты привлекательно представляют культуру народов России, стимулируют мотивацию учащихся. Музыка, отметим, всегда оказывает благоприятное эмоциональное воздействие, вследствие чего происходит лучшее запоминание слов, конструкций, смысла.

По мнению И. А. Стернина, «песнями в России приветствуют, величают, провожают, поддерживают, воодушевляют, жалуются, ищут сочувствия и помощи, благодарят - палитра коммуникативных функций русской песни необычайно широка и практически совпадает по диапазону с основными функциями русского общения» [Стернин, с. 3].

Итак, уроки литературы, уроки чтения помогают повысить интерес иностранных учащихся к чтению на русском языке. Отбор тех или иных прозаических и поэтических текстов происходит в том числе и с учетом национально-региональной культуры. Чтение, бесспорно, повышает их культурную грамотность. Художественные произведения являются неким ключом для понимания чужих изучаемых культур, которые могут отражать другие национальные ценности более ярко, понятно, конкретно.

Подытоживая вышеизложенное, укажем, что изучение поэзии на уроках русского языка как иностранного открывает широкие возможности для успешного обучения учащихся, способствует совершенствованию социокультурной компетенции, знакомит иностранных учащихся с богатым культурным наследием страны изучаемого языка, помогает улучшить навыки понимания текстов, дает им возможность понять метафоричность языка, совершенствует их эстетический вкус, прививает любовь к звучащему образному слову. Важно, что поэзия вносит неоценимый вклад в нравственное воспитание. Многие поэтические жанры отражают нравственные ценности (красоту души, преданность, верность, честность, мужество, скромность, ответственность, любовь к родине и др.).

Лuтература

1. Батудаева Д. Баир Дугаров: «Человеку нужно попасть в среду себе подобных». URL: https://minkultrb.ru/news/news/12375-bair-dugarov-cheloveku-nuzhno-popast-v-sredu-sebe-podobnykh/ (дата обращения: 01.11. 2021). Текст: электронный.

2. Дампилова Л. С. Миф и история в «Тэнгрианских песнях» Баира Дугарова. URL: https://mif-iistoriya-v-tengrianskih-pesnyah-baira-dugarova (дата обращения: 04.11. 2021). Текст: электронный.

3.Дугаров Б. С. Струна земли и неба. Стихотворения. Улан-Удэ: Республиканская типография, 2008. 360 с. Текст: непосредственный. 
4.Имихелова С. С. Поэт в контексте эпохи: о первом опыте литературной биографии Баира Дугарова // Вестник Бурятского гос. университета. Сер.: Литература. Литературоведение. Устное народное творчество. 2017. № 3. С. 45-50. Текст: непосредственный.

5. Миксюк Р. В. Художественный текст на уроках русского языка как иностранного // Высшее техническое образование. 2019. Т. 3, № 1. С. 59-62. Текст: непосредственный.

6.Кулибина Н. В. Читаем стихи русских поэтов. Санкт-Петербург: Златоуст, 2008. 96 с. Текст: непосредственный.

7. Кулибина Н. В. Зачем, что и как читать на уроке. Санкт-Петербург: Златоуст, 2015. 224 с. Текст: непосредственный.

8. Лихачев Д. С. Концептосфера русского языка // Русская словесность / Ин-т народов России. Москва, 1997. С. 280-287. Текст: непосредственный.

9.Смирнов В. П. Поэзия в России равновелика религии. URL: https://ufa.bezformata.com/listnews/poeziya-v-rossii-ravnovelika-religii/97817520/ (дата обращения: 01.11. 2021). Текст: электронный.

10. Стернин И. А. Песня и русское общение // Коммуникативные исследования / под редакцией И. А. Стернина. Вып. 18. Песня как коммуникативный жанр. Воронеж: Истоки, 2015. С. 3-6. Текст: непосредственный.

Статья поступила в редакцию 02.10.2021; одобрена после рецензирования 13.10.2021; принята к публикачии 15.12.2021.

\title{
ON THE STUDY OF POETIC TEXTS IN THE LESSONS \\ OF RUSSIAN AS A FOREIGN LANGUAGE
}

\author{
Galina V. Ulazaeva \\ Candidate of philological sciences, Associate Professor \\ Dorzhi Banzarov Buryat State University \\ 24 a Smolina St., Ulan-Ude, 670000, Russia \\ diskurs@mail.ru \\ Ayuna K. Khabdaeva \\ Doctor of philosophical sciences, Associate Professor \\ Dorzhi Banzarov Baikal State University \\ 11 Lenina St., Irkutsk, 664003, Russia \\ ayupost@yandex.ru
}

One of the important tasks in teaching Russian as a foreign language (RFL) is immersion of a foreign student into the cultural environment of the target language. And one of the means of implementation of this task is the study of Russian poetry. A special place is given to working with poetic texts in the lessons of Russian as a foreign language. A literary text is an effective means of bringing foreign students closer to the natural linguistic and cultural environment; it is a separate model of national culture. Based on the principle of the close interrelation of language and culture, it is important to acquaint foreign students with the culture of different peoples living on the territory of Russia. «The Star of the Nomad» poem by a famous Russian writing Buryat poet Bair Dugarov is the example of independent cognition and perception by foreign students.

Keywords: Russian as a foreign language, socio-cultural competence, model of national culture, two linguistic worlds, poetic text, translation.

The article was submitted 02.10.2021; approved after reviewing 13.10.2021; accepted for publication 15.12.2021. 